\title{
The Music of Tomorrow, Yesterday! Music, Time and Technology in BioShock Infinite
}

\author{
ANDRA IVĂNESCU, Anglia Ruskin University
}

\begin{abstract}
Filmmakers such as Kenneth Anger, David Lynch and Quentin Tarantino have taken full advantage of the disconcerting effect that pop music can have on an audience. Recently, video games have followed their example, with franchises such as Grand Theft Auto, Fallout and BioShock using appropriated music as an almost integral part of their stories and player experiences. BioShock Infinite takes it one step further, weaving popular music of the past and pop music of the present into a compelling tale of time travel, multiverses, and free will. The third installment in the BioShock series has as its setting the floating city of Columbia. Decidedly steampunk, this vision of 1912 makes considerable use of popular music of the past alongside a small number of anachronistic covers of more modern pop music (largely from the 1980s) at crucial moments in the narrative. Music becomes an integral part of Columbia but also an integral part of the player experience. Although the soundscape matches the rest of the environment, the anachronistic covers seem to be directed at the player, the only one who would recognise them as out of place. The player is the time traveller here, even more so than the character they are playing, making BioShock Infinite one of the most literal representations of time travel and the tourist experience which video games can represent.
\end{abstract}

\section{KEYWORDS}

Video game music, film music, intertextuality, time travel.

\section{Introduction}

For every choice there is an echo. With each act we change the world [...] If the world were reborn in your image, Would it be paradise or perdition?

(BioShock 2 launch trailer, 2010)

Elizabeth hugs a postcard of the Eiffel Tower. Behind her the player can see child-like drawings of the 'Songbird', a sixty-foot metal bird-like creature that acts both as her prison guard and as her protector and only friend. She turns to a painting that depicts the illuminated Eiffel Tower at night with a background of electric-blue sky. She strenuously opens a portal through space and time that quickly turns from black and white to colour and 
the player may get a feeling that this is something she does frequently. 'Everybody Wants to Rule the World' by Tears for Fears can be heard in the background and the player can see a cinema listing of a Star Wars film as an ambulance rushes towards her, forcing her to close the portal quickly, almost in a panic. Booker Dewitt, the player character, is perplexed. The player, however, knows that what they saw was a glimpse of 1980s Paris, certainly not 1912 Columbia. This is nevertheless part of the world of BioShock Infinite (Irrational Games, 2013), the third and final installment of the BioShock series.

The scene described above reveals many of the themes that will be discussed in this article, specifically how an almost transdiegetic approach is justified through the in-game device of time-travel. The role pre-existing music plays in the BioShock games, particularly in BioShock Infinite, will be explored in relation to narrative and the concept of ludo-narrative dissonance.

Despite its novelty, the field of ludomusicology (the study of video game music) has already benefited from a variety of approaches, from the ethnomusicological to the phenomenological, with many researchers offering historical perspectives, technological ones, and many also focusing on functionality. Zach Whalen describes two types of functions in his article 'Playing Along: An Approach to Videogame Music': those that 'expand the concept of a game's fictional world' and those that 'draw the player forward through the sequence of gameplay' (2004). Indeed, most subsequently-identified functions of audio and music in games fall under one or both of these categories. For instance, examples of functions that fall under the latter category are sound and music that alert the player of imminent danger (Collins 2008) or acousmatic sound and music (Chion 1994) that draw the player's attention or guides the player in a certain direction (Collins 2008; Gibbons 2011). Among the functions that expand the fictional world, many are maintained from film music, such as indicating geographical space or historical time. Somewhat central to both video game music scholarship and video game scholarship in general is the idea of immersion, as 'diminishing critical distance to what is shown and increasing emotional involvement in what is happening' (Grau 2003). Although all of the above functions (and more) are fulfilled by the music in the BioShock series, immersion is also, seemingly counter-intuitively, subverted. This article argues that anachronistic cover versions of pre-existing popular music in BioShock Infinite can work to increase critical distance and encourage self-reflexivity, exploring how self-reflexivity is perhaps as central to video games as immersion is largely considered to be.

\section{The worlds of BioShock}

Unlike the first two games of the series - BioShock (Irrational Games, 2007) and BioShock 2 (2K Marin, 2009) - which are set in the dystopian city of Rapture, BioShock Infinite is set in the seemingly utopian floating city of Columbia. At first glance, Rapture and Columbia are worlds that could not seem further appart. Rapture is an underwater dystopia with an Art Deco aesthetic, whereas Columbia is a flying utopia with a Neoclassical style. However, the similarities between the two soon outnumber their differences and they become analogous parables. 
Rapture is an underwater city, forcing the player to undergo both a literal and a metaphorical descent, whereas the journey to Columbia is masked as a literal and moral ascent into what the player is told is 'Heaven, son, or as close as we'll see 'till judgment day' (BioShock Infinite). Videogame scholar Grant Tavinor describes Rapture as 'portrayals of decaying art deco facades, faded Hollywood socialites, and echoes of Hearst, Hughes, and Citizen Kane', which 'are combined with period music and philosophical and literary references to produce a coherent artistic statement' $(2009,91)$. Although set in the 1960s, Rapture is a fallen utopia built in the 1940s, with beautiful façades and spectacular art deco architecture, referencing not only a real moment in history but, as Tavinor intimates, also the constructed reality of 'classic' Hollywood glamour. But Rapture is more than that; it is the embodiment of one man's beliefs, his personal paradise, built upon the ideas of objectivism. Although the game has been read as a critique of objectivist views (Packer 2010), it can easily be argued that it is more of a comment on any form of ideological extremism. This latter assertion is confirmed by the two subsequent games, which put forward different ideals and utopias that inevitably fail. As Ken Levine, creator and lead writer of the series, said, 'It's a cautionary tale about wholesale, unquestioning belief in something' (cited in Crecente 2008).

The city of Columbia is surprisingly similar: this vision of 1912 is also the vision of one man - not Andrew Ryan, the mastermind behind Rapture, but the prophet Zachary Hale Comstock. The neoclassical architecture and the warm elegance of the décor and the costumes build towards an even brighter vision of this alternate past. The sky is baby blue, and this paradise is not yet fallen but on the brink of revolution. Comstock's racist reign is taken down during the game by Daisy Fitzroy and her Vox Populi, and the new regime proves to be just as brutal, becoming the third incarnation of failed utopia.

There are even more analogies to be found between the two cities. Steampunk elements are ubiquitous, from the diving-suit-clad Big Daddies of Rapture to the heavily armored Handymen of Columbia. You travel to both cities through a lighthouse; in Rapture you undergo a literal descent as well as a metaphorical one, whereas Columbia forces you to ascend through the clouds. Later, the lighthouse is presented as a nexus, as an entry point to all possible parralel worlds, and it can easily be interpreted as a common symbol for hope and guidance. The lighthouse is the door and both characters-Jack and Booker DeWittwillingly walk through it. The fundamental difference between the two, however, is that Jack, the player character in BioShock, finds himself trapped: after a plane crash he has nowhere else to go but down into the underwater city to which he is thereafter confined. Booker DeWitt chooses to go to Columbia in search of Elizabeth, the customary damsel in distress, and finds himself in a world where 'tears' act as portals into both different times and parallel universes. ${ }^{1}$ The floating city then becomes the setting of a compelling tale of time travel, multiverses, and free will. These tears through time and space account for a number of intentional anachronisms in the game, many of them musical. In fact, appropriated music and popular music in particular play an essential part in the entire series, both as a temporal signifier and as a contributing factor to the anachronistic world. Popular music is here understood as one of Philip Tagg's axiomatic triangle of 'folk', 'art' and 'popular' music, of which popular music is described as having the following distinguishing characteristics: '(1) conceived for mass distribution to large and often socioculturally heterogenous groups of listeners, (2) stored and distributed in non-written form, (3) only possible in an industrial monetary economy where it becomes a commodity, and (4) in capitalist societies, subject to the laws of "free" enterprise, according to which it should ideally sell as much as possible of 
as little as possible to as many as possible' (Tagg 2000). ${ }^{2}$ This paper focuses mostly on popular music, which is used predominantly in the games, although the pre-existing music spans all three categories mentioned by Tagg.

\section{Beyond the sea}

The BioShock series uses significant amounts of appropriate or pre-existing popular music. The popular music used in BioShock and BioShock 2 functions on a number of textual levels. Musicologist William Gibbons places it 'along something of a continuum, with those that embody or reflect on the general dystopian environment (mostly ironically) on the one end, and those that zoom in to focus more directly on the action at hand at the other' (2011). Within the first two games the music works both as part of the whole aesthetic, as well as a lyrical commentary on either the action of the game, its spaces, or other details. Talking about the first category of functions, Gibbons mentions that:

On one level, this borrowed music signifies the time period evoked by the game, grounding the action in the mid-century despite the presence of futuristic technology, acting as a constant reminder of the aesthetic and cultural values of the predystopian American culture, creating a dichotomy between its optimism and the dystopian environment of BioShock. (2011)

Referring to the second category of functions, he describes it as follows:

This style of title-based musical 'pun' evokes the silent-film era practices of cinema pianists, who could quickly choose tunes with titles that corresponded (at least tangentially) with the action on screen-something that carried over into the sound era, particularly in the animated shorts scored by figures like Carl Stalling. (Gibbons 2011)

A relevant example of how borrowed music works in the BioShock series is 'Beyond the Sea' (in at least two different recordings), which acts almost as a theme tune in the first BioShock game. Players are somewhat prepared to recognize and associate the song with the game even before they have played the game with Bobby Darin's 'Beyond the Sea' (1960) introduced in the game's trailer. The player is thus familiarized with both the world and its music, the latter being presented as an integral part of the first.

The song is also the first popular song heard in the game itself. As Jack enters the lighthouse, the earlier instrumental version of the song_- 'La Mer' (1949)_-performed by Stéphane Grappelli and Django Reinhardt, can be heard. The music guides the character and the player down the stairs of the lighthouse, to the underwater dystopia. 'Almost imperceptibly, music sneaks into the scene, and players gradually become aware of the quiet sound of a violin and a guitar' (Gibbons 2011). The music seems to be non-diegetic at first, disembodied in a way that is accentuated by the absence of lyrics, but is soon proven to be diegetic, as the player discovers its source (a radio) upon entering the Bathysphere leading into Rapture. Although 
this is an instrumental version of the song, it can be argued that if the player is familiar with the song-even if only from the game's trailer-the lyrics are not non-existent. This is why Gibbons looks at the possible impact of the lyrics of the English version of the song on a player:

The lyrics, assuming the player knows them, reinforce the idea of travel to a better place; a life filled with love and happiness awaits the narrator 'somewhere beyond the sea'. The song seems to speak directly to the heart of the situation at hand, suggesting that should Jack only take a trip through the bathysphere, passing beyond the sea-though a vertical route was probably not what the songwriter intended-he will reach the end of his journey: Rapture. This optimism, however, soon reveals itself to be painfully ironic, as the utopian promises made by the song have long since dissipated. (2011)

BioShock 2 does not seem to have a theme song that operates in the same way. However, the launch trailer does feature the song 'Daddy, Won't You Please Come Home' (1929), performed by Annette Hanshaw. The song also features in the game itself. The lyrics work as a lyrical pun and, like 'My Heart Belongs to Daddy' (Eddy Duchin and His Orchestra, featuring Mary Martin, 1938), reference a Big Daddy, the character you play in this second instalment of the series. At the same time, the light tone of the songs creates the same type of effect as in BioShock 2, accentuating the contrast between predystopian optimism and the 'current' dystopia.

The third instalment of the series introduces an even clearer example of such a 'theme song': 'Will the Circle Be Unbroken' appears throughout the game in two main versions (choir and duet). The song is not the first the player hears in the game, and it cannot be heard in most of the trailers, with the exception of the Video Game Awards 2011 trailer. The first song featured is in fact Polk Miller's version of '(Give Me That) Old Time Religion', heard on the radio, followed by a version of 'Will the Circle Be Unbroken' as Booker DeWitt first enters Columbia. While both songs set the scene, since both are temporally and thematically relevant in that they mention religion, the latter becomes a theme for the whole game in a very similar manner to 'Beyond the Sea' in the first BioShock game.

'Will the Circle Be Unbroken' is immediately relevant, its lyrics asking, 'Is a better home awaiting / In the sky, in the sky?' as Booker ascends into the floating city of Columbia. The lyrics, as their counterpart in 'Beyond the Sea', speak of hope and salvation, although the context is religious in this instance.

The lyrics, however, become more and more pertinent throughout the game:

In the joyous days of childhood

Oft they told of wondrous love

Pointed to the dying Saviour;

Now they dwell with Him above 
These lyrics also seem to refer to Zachary Hale Comstock, the prophet, who, as the story unfolds, proves to be dying. He can certainly be seen as a cult leader and messianic figure. However, the lyrics of the hymn become even more poignant at the end of the game: Booker DeWitt and Zachary Hale Comstock are revealed to be different versions of the same person, brought together by Rosalind/Robert Lutece. He then chooses to save the world by sacrificing himself, thus 'breaking the circle' and preventing any versions of himself from continuing to live. The lyrics of the song are, as with 'Beyond the Sea' taken literally, at least to begin with. The salvation seems to lie in the sky; that is, in the city of Columbia. However, as is revealed at the end of the game, the original, metaphorical meaning seems in fact to be the appropriate one and salvation might lie not in the actual sky but in death and the heaven that Booker might reach after it.

\section{More music in BioShock: Infinite}

BioShock Infinite uses more borrowed music than the first two installments of the series and in a more diversified way. Ken Levine, creative director and lead writer, describes the direction that was chosen for the original score of the game, ideas which can additionally be applied to the borrowed music:

To me, this game has much more of an American feel to it. We wanted a bit more of a frontier feel to it, slightly. It would be very easy to go in a bad direction with that. It could be very Civil War-y or very Wild West-y. The Bonanza theme. That kind of thing. It's not what I wanted. I think probably the biggest inspiration for me was Johnny Greenwood's score for There Will Be Blood. He's one of the musicians in Radiohead. He did this wonderful, incredibly spare score. That was a good starting point. There's some influence from the score for 12 Monkeys in Garry [Schyman]'s score. And then there's just Garry. (Goldfarb 2013)

The music of BioShock Infinite does indeed have many qualities that make it similar to the two film soundtracks mentioned: There Will Be Blood (Paul Thomas Anderson, 2007) and 12 Monkeys (Terry Gilliam, 1995). It is, as Levine states, sparse. Unlike the music of the first two games, it is more tactile (although timbre and texture seem to be preoccupations in all three), suggesting intimacy and open space at the same time - perhaps an appropriate musical interpretation of a floating city where you are trapped despite the sky being the limit.

The open space is, however, filled with diegetic music, which also seems to capture the 'American feel' that Levine describes, the songs lyrically describing themes relevant to turnof-the-century America. The appropriated music is also more specifically related to the narrative and is triggered by specific actions or appears at specific moments in the narrative. Whereas in the first two games songs belong to certain spaces and play as musical cues when you enter them, in Infinite anachronistic covers seem to belong more to moments in the narrative and be triggered by certain unavoidable actions. For instance, 'Brother, Can You Spare a Dime' is playing in Fontaine's Home for the Poor in BioShock, while 'Girls Just Want to Have Fun' is triggered by Booker convincing a dancing Elizabeth to stop follow him by promising to take her to Paris. Nevertheless, the appropriated music of Infinite functions similarly to the appropriated music of the first two BioShock games. It acts as both temporal signifier and as either a lyrical pun or a broader thematic link. For instance, '(Give Me That) 
Old Time Religion', a spiritual, the oldest appearing popular song, reflects two major themes of the game: religion and racial tension. Spirituals have been considered 'not merely quantitatively but qualitatively the antebellum slaves' most significant musical creation' (Levine 1978, 19). As well as an essential part of the culture of African American slaves, spirituals have also been enlisted as 'cultural weaponry in the symbolic arsenal against slavery' before and during the Civil War (Cruz 1999, 3). '(Give Me That) Old Time Religion' carries within it the unavoidable cultural, political and historical associations of the genre, thus reflecting the larger problems tackled throughout the game: Columbia is an undoubtedly racist society, where the prize of a raffle is throwing the first baseball at an interracial couple, and the Fraternal Order of the Raven honour John Wilkes Booth by having a statue of him in the foyer of their headquarters, as well as a painting of him assassinating Abraham Lincoln elsewhere. Racial tensions come to a head when the insurgency group the Vox Populi revolt against the oppressive Founders, the major political party of Columbia. '(Give Me That) Old Time Religion' only plays on a phonograph inside the Lighthouse, but other songs by the same performers-Polk Miller and the Old South Quartette-play throughout the game, including a version of 'The Bonnie Blue Flag', a song associated with the Confederate States of America. It is tempting to further interpret the choice of a white performer's version of '(Give Me That) Old Time Religion' as significant, especially when considered alongside the same performer's version of 'The Bonnie Blue Flag'. However, it is also possible that the fact they seem to be two of the oldest available recordings of the songs is more significant.

The appropriated music that can be considered 'of the time', in that they would likely not be strikingly anachronistic to a layperson, and works as a temporal signifier thus ranges from 1873 until 1941. Although some of these songs may be considered anachronistic, they are not treated as such, being plausibly 'of 1912' in this alternate reality. Every place in Columbia, from club headquarters to private rooms and even the crypt all have their own designated music. For instance, popular music plays in all the bars, club headquarters, plazas, shops in the city of Columbia: Helen Kane's 'Button Up Your Overcoat' (1929) plays in the abandoned bar in Emporia Towers, while Rudy Vallée's version of 'Makin' Whoopee' plays in The Salty Oyster. Virtually every phonograph plays a different song.

There are, however, songs that seem more relevant in context than others. Lead Belly's 'Goodnight, Irene', for instance, is sung by what is effectively a lynch mob at the Raffle, competing for the first baseball that is thrown at an interracial couple. Another example is Jessy Carolina's version of 'After You've Gone', specially recorded for the game. It can be heard both in Monument Island and Comstock House, and the lyrics can be interpreted as being addressed to Elizabeth and her attempt to escape Columbia.

There are also a number of classical pieces that can be heard throughout the game. For instance, fragments of Mozart's Requiem can be heard at Lady Comstock's Grave, Johann Sebastian Bach's Air on the G String plays at the Cult of John Wilkes Booth, and Chopin's Nocturne in E-flat major can be heard in Finkton (the exploitative factory district run by Jeremiah Fink). The situations in which they appear and the people to whom they are connected (the prophet Comstock and Lady Comstock, John Wilkes Booth, Finkton and the people on the Raffle Stage), imply that classical music is, to a certain extent, representative of the oppressive white upper class. 


\section{Anachronistic covers in BioShock Infinite}

The most compelling musical addition in BioShock Infinite is the anachronistic cover. These are 'modern hits' rearranged in a style that is more temporally appropriate. These seem to be more intimately linked to the narrative. The first one to be heard is a version of 'God Only Knows' (Brian Wilson and Tony Asher, 1966), sung in-game (appearing diegetically) by a barbershop quartet in a floating gondola. 'God Only Knows' is an interesting choice, as using the word 'God', which is probably one of the reasons it is present in BioShock Infinite, was in itself problematic at the time of the song's writing: Tony Asher explains that he and Brian Wilson

had lengthy conversations during the writing of 'God Only Knows', because unless you were Kate Smith and you were singing 'God Bless America', no one thought you could say 'God' in a song. No one had done it, and Brian didn't want to be the first person to try it. He said, 'We'll just never get any air play'. Isn't it amazing that we thought that? But it worked. (quoted in Granata 2003, 442)

The song appears in the game before the existence of tears through time is known, so it is the first hint that the universe is more than just an alternate reality story. It is also the first time Albert Fink's name is introduced, and it is implied that he is the 'composer' of all the anachronistic covers in the game.

An anachronistic cover of 'Everybody Wants to Rule the World' by Tears for Fears (Roland Orzabal, Ian Stanley and Chris Hughes, 1985) can be heard in the Magical Melodies studios of Albert Fink. The original version of the song can be heard briefly through the first tear that the player sees. The song plays as the player sees the Eiffel tower and a cinema sign announcing La revanche $d u$ jedi, the French translation of the working title of the 1983 film Star Wars: Episode VI-Return of the Jedi. Another example is 'Girls Just Want to Have Fun.' Although originally written and recorded by Robert Hazard in 1979, the song reached chart success in the mid-1980s in Cyndi Lauper's interpretation. The latter also seems to be the version covered here, as is implied by the appearance of the Cyndi Lauper version of the song in the game, through a tear in Albert Fink's office. The cover version of 'Girls Just Want to Have Fun' appears in Battleship Bay. After Elizabeth runs off enjoying her freedom and Booker finds her dancing on the beach, 'Girls Just Want to Have Fun' is triggered by Booker's actions, specifically by Booker interrupting Elizabeth's 'fun' and taking her away, thus moving the story along. The song, played on a steam organ, evokes an American seaside feel, and is significantly different from the original. It can be considered an Easter egg (a hidden message, often a joke) of sorts as it may go unnoticed by the player. However, if it is noticed, the invisible lyrics of the song carry meaning that is relevant to both the situation at hand and the larger plot of the game.

The immediate message of the scene seems quite clear: Elizabeth is enjoying her new-found freedom and the song is an echo of her feelings towards Booker in this particular scene. She does not want to follow Booker and continue the mission; she wants to enjoy her life, perhaps follow her dream of going to Paris. Looking even more closely at the implied lyrics, they 
seem even more appropriate, specifically this verse: 'Some boys take a beautiful girl / And hide her away from the rest of the world / I want to be the one to walk in the sun / Oh girls they want to have fun'. This seems to refer directly to Elizabeth's imprisonment in the tower on Monument Island. Watching the scene again after having completed the game, the invisible lyrics seem even more poignant retrospectively.

Covers of 'Tainted Love' (Ed Cobb, 1965), 'Fortunate Son' (John Fogerty, 1969) and 'Shake Sugaree' (Elizabeth Cotten, 1967) are covers that can be heard at different times in Shantytown, the (predominantly African-American and Irish) poor working class area in Columbia. While 'Tainted Love' seems to be mostly atmospheric and can be heard in the Graveyard Shift Bar, the other two songs can be seen to act as the voice of the people more than the 'Vox Populi', the secret organization planning a revolt. The Elizabeth Cotten song 'Shake Sugaree' is played by three children and reflects the poverty of the ghetto:

Pawn my watch,

Pawn my chain,

Pawn everything that was in my name.

Oh, lordy me,

Didn't I shake sugaree?

Everything I got is done and pawned,

Everything I got is done and pawned.

'Fortunate Son' is sung by a woman in the same area, only it is sung after the revolution. The Creedence Clearwater Revival anti-war anthem seems to reflect the people's feelings after the revolution:

Some folks are born to wave the flag,

Ooh, they're red, white and blue.

And when the band plays 'Hail to the chief',

Ooh, they point the cannon at you, Lord,

It ain't me, it ain't me, I ain't no senator's son, son.

It ain't me, it ain't me; I ain't no fortunate one, no,

Yeah!

Some folks are born silver spoon in hand,

Lord, don't they help themselves, oh.

But when the taxman comes to the door,

Lord, the house looks like a rummage sale, yes,

It ain't me, it ain't me, I ain't no millionaire's son, no.

It ain't me, it ain't me; I ain't no fortunate one, no.

Some folks inherit star spangled eyes,

Ooh, they send you down to war, Lord,

And when you ask them, 'How much should we give?' 
Ooh, they only answer More! more! more! yoh,

It ain't me, it ain't me, I ain't no military son, son.

It ain't me, it ain't me; I ain't no fortunate one, one.

The themes of the song resonate with the themes of the game: the critique of excessive nationalism, the oppressive upper classes exploiting the poor and the war that not everybody supported. It is interesting, though, that the oppressed seem to be disillusioned with the revolution itself. The children singing 'Shake Sugaree' are gone and the new rule is just as bad as the old one.

The last anachronistic cover to be mentioned is Tony Babino's version of the R.E.M. song 'Shiny Happy People'. The song's existing political connotation make its meaning relatively clear in context. Borrowed music in BioShock Infinite once again acts both as a temporal signifier and a lyrical pun, but it contributes far more to the disconcerting anachronistic feel of the game and seems to be much more closely linked to the narrative.

\section{The meta-game}

Music in BioShock Infinite operates like the Proustian madeleine, acting as a constant reminder to the player, although through sound as opposed to smell. The player becomes the tourist through time and space, noticing anachronisms that the characters in the game, even the playable character, would not be able to identify. The game and its music show the player the cracks forming in the fourth wall, reminding them that they are just a player. Music plays an essential part in this process. Perhaps it is not as overt as Count Basie's orchestra turning up in the desert in Mel Brooks' Blazing Saddles (1974), but it is nearly as funny and just as effective, if not more so.

It is, however, important to remember that the fourth wall is not as sturdy in video games as it is in films, for instance. As a medium that evolved in a postmodern age, video games are particularly self-reflexive and self-aware, constantly questioning what video games are and trying to push beyond those limits.

Recent indie games seem to be doing little else but exploring boundaries. Quirky platformers Braid (Number None, Inc. and Hothead Games, 2009) and Fez (Polytron, 2012) redefine genre by putting a twist on a classic one, the former introducing time manipulation into the mix, while the latter introduces 3D into a fundamentally 2D world. At the same time, exploratory games like Proteus (Ed Key and David Kanaga, 2013) and Dear Esther (The Chinese Room, 2012) question the very definition of video games, removing elements that might seem an essential part of a definition such as goals and conflict. Debates around these so-called art games has even sparked a Twitter account called@TheGamePolice, a comical entity (or perhaps a clever marketing tool) that points out art games that may not be games at all: 'Ludic Fraud is an issue we take extremely seriously' (Twitter, January $31^{\text {st }} 2013$ ). 
This deconstructivist attitude is, however, neither new nor limited to indie or art genres. Despite increasingly immersive user interfaces, there is a long tradition of soliloquies and other little nods that break the fourth wall. In fact, Kristine Jorgensen finds the muddling of lines between diegetic and extradiegetic space inherent to the medium, as is it a 'combination between fictional world and user system' (Jorgensen 2007, 12). The BioShock series does not do this directly, but undertakes a subtle 'deconstruction of interactivity' (Tulloch 2009), gradually forcing the player to consider the limitations of their choices. In the first game, the only significant choice you can make is whether to 'save' or 'harvest' 'Little Sisters'. Little Sisters are young orphaned girls who in turn harvest ADAM, a substance Jack requires to advance through the game. Saving the girls gives you less instant ADAM, whereas harvesting them gives you a substantial amount. Lars Schmeink has seen this as a series of choices that can place the character in a number of places along a moral compass:

If we consider the options, a player has several possible lines of action. The player can stay on the moral high ground by healing all of the Little Sisters, he can defile them all, or any range of choices in between sometimes healing, sometimes defiling (Schmeink 2009).

However, BioShock still only offers the player 'a single major moral choice repeated continually throughout the game' (Schulzke 2009, citing Tavinor 2009). Nevertheless, the game still forces the player to consider the morality and the consequences of their in-game actions. A poignant moment of reflection is the twist in the first game. From the beginning, the lead character, Jack, is guided through Rapture by Atlas via radio. After you help him defeat Ryan, the 'evil ruler' of Rapture, Atlas is revealed to be an equally corrupt villain seeking power and he betrays you. As videogame theorist Rowan Tulloch notes, 'This twist functions to reveal two parallel manipulations: Atlas' manipulation of Jack, and the game's manipulation of the player' (Tulloch 2009). In other words, this twist may make the player question her own obedience towards the game. This can be compared to psychological experiments where subjects model their behaviour on what they feel the scientist is expecting of them (this has been said of the Stanford prison experiment, for instance).

In the case of video games, players may reflect on how often they model their gameplay after what they feel the game expects of them. For instance, in the controversial optional mission 'No Russians' in Call of Duty: Modern Warfare 2, the player character, who is under cover in a terrorist cell, takes part in a massacre of civilians at an airport. Although the player cannot kill the other terrorists and prevent the massacre, they do not have to engage in the massacring of civilians. However, the player might not realize that this is a choice and may feel compelled to open fire. This is just one example where players are made to examine their own moral choices in a video game, and moral choices themselves are not a rarity in video games. However, the BioShock series evolves into a different exploration of the idea of choice.

In BioShock Infinite the player only has a limited number of choices, none of which seem to affect the game. One of the most conspicuous examples is choosing the symbol that will appear on Elizabeth's choker. The player has a choice between a cage and a bird, symbols that would seem to have opposite meanings, one of confinement and one of freedom. The 
choice literally only affects the cameo on her chocker and acts as a permanent reminder of the futility of your choices.

Fatalism seems to be the key concept of BioShock Infinite, as objectivism is the key concept in BioShock. This can be interpreted as a comment of the illusion of choice players have in video games in general. No matter how open-world a sandbox game is, there is still only a limited number of choices the player can make, which result in a finite number of possible endings. In BioShock Infinite, the player is confronted with the limitation of choice and its consequences. Game developer Clint Hocking has noted this limitation and has coined the term 'ludonarrative dissonance' (Hocking 2007) to describe the discordance between the narrative and the game mechanics. As he has noted, the apparent choice between good and gain is in fact not clear at all. Although there is a choice of 'saving' or 'harvesting' the Little Sisters, there is no choice of whether to help Atlas, your guide throughout the game, or to help Ryan, thus making the player unable to truly follow the Randian self-interest. Hocking sees this as a conflict between the 'ludic contract' and the 'narrative contract'. This conflict is emphasized even more by the fact that even the repetition of choice regarding the Little Sisters is not essential to gameplay, as the 'good' path does no longer present itself as much more difficult. Saving the Little Sisters gives the player a similar number of advantages in the long run as harvesting them would, making the difference in gain insignificant, making the moral choice even more poignant. Hocking calls this ludonarrative dissonance 'disturbing' and continues to state that, 'The game openly mocks us for having willingly suspended our disbelief in order to enjoy it' (Hocking 2007). This is seen as a problem by Hocking, but in light of the entire series it may be seen as an invitation to self-reflection. This lack of choice is even justified in-game, as the player-character himself is revealed to be conditioned to follow Fontaine's (Atlas's) orders at a crucial moment in the narrative, and is proved to have no real choice in the gameworld. Then, the player-character is forced to murder Andrew Ryan. This is a moment that, as Roger Travis indentifies, emphasizes some of the themes previously discussed:

As he is accepting death at the player-character's hands, Ryan repeats over and over 'A man chooses; a slave obeys'. He, and BioShock, however, demonstrate just as Plato's cave-culture-game demonstrates, that the dangerous illusion of choice presents the true ethical problem. (Travis 2010, 99)

Although the BioShock games often break the illusion with a wink and a nod, immersion is still essential. In fact, without immersion, the winks would not have the same desired effect, as there would be no illusion to break. Like many other games, the BioShock series employs clever tactics to give the player the illusion of freedom or to make confinement feel natural, justifying the limitations of the game and the gameworld. Both Rapture and Columbia are cities where the player is effectively trapped, either under water or in the sky and escape is difficult if not impossible. In his exploration of ethical education in BioShock through a comparison with Plato's Republic, Travis says that the two works 'invite us to imagine a way to make ethical choices without presuming that those choices are freely made. There is no way to avoid being trapped in the game; but being aware of the experience of being trapped can teach us to make and play better games, with better, though never freer, choices' (Travis 2010, 99). 


\section{Music and the meta-game}

Music guides players through these choices, sometimes directly, sometimes indirectly; it guides the player directly in that it results in immediate action, and it guides the player indirectly in that it can enhance or subvert immersion and influence the choices the player makes. In the BioShock series, music plays an essential part in both drawing the player in and pushing the player away.

'Active offscreen sound', described by Michel Chion (1994) as 'acousmatic sound that raises questions-What is this? What is happening? - whose answer lies offscreen and which incite the look [or, in our case, the player] to go there and find out', is present throughout the BioShock games. As Gibbons points out, the player's first encounter with pre-existing music is, in fact, one of this kind, where the player follows the sound of a radio playing 'Beyond the Sea' into the bathysphere that takes her to Rapture (Gibbons 2011). Another example are leitmotifs that may alert the player to the presence of certain characters and draw their attention to them, as does the Lutece motif throughout BioShock Infinite.

On the other hand, music can influence the player indirectly. The pre-existing music in all three games can be described as what Chion calls 'anempathetic', seeing as it exhibits 'conspicuous indifference to the situation, by progressing in a steady, undaunted and ineluctable manner' (Chion 1994). There is, perhaps, an inherent indifference to appropriated music in video games, because, unlike in film, the pace of a scene can rarely be controlled, as individual players have their personal styles of play and levels of ability. Therefore, the way the music synchronizes with visual and kinetic elements is not as controlled as it would be in a film, for instance. There is, however, more to the indifference of the music in the BioShock games. Although the lyrics of the songs reflect some of the themes and particular situations in the games, their tones strongly contrast with that of the games: cheerful and optimistic songs-sometimes novelty ones such as 'How Much is that Doggie in the Window' (Bob Merrill, 1952) or 'Papa Loves Mambo' (Al Hoffman, Dick Manning and Bix Reichner, 1954) - present a stark contrast to the violence of the dystopian environment, often intensifying emotion, and at other times - and even simultaneously - to humourous effect.

The anachronistic covers in BioShock Infinite are, however, exceptions on a number of accounts. First of all, they do not seem to fulfil practical, direct functions. Despite the fact that they appear in important narrative moments, they can easily be missed or overlooked by a player, proved by the fact that they are often described as Easter eggs. At the same time, unlike most of the rest of the appropriated music in the games, they can be seen as 'empathetic' in that they 'directly express [...] participation in the feeling of the scene' (Chion 1994). For instance, 'Fortunate Son' reflects the feelings and emotions of the people of Shantytown after the revolution. These are moments of emotional resonance, and, just like the aforementioned madeleine, evoke emotion as well as memory. It can therefore be argued that the music enhances and subverts immersion simultaneously. 


\footnotetext{
${ }^{1}$ Rosalind Lutece and her male counterpart from a parallel universe, Robert Lutece, are responsible for the existence of Columbia itself and most of the other unusual technological advancements present in the game. ${ }^{2}$ A more detailed analysis of the term 'popular music' and its possible definitions can be found in Roy Shuker, 'Understanding Popular Music Culture' (2012).

${ }^{3}$ In a pre-release version of the game the name of the quartet is written behind the singers on the gondola as The 'BEE' Sharps as a reference to Homer Simpson's barbershop quartet The Be Sharps in The Simpsons episode 'Homer's Barbershop Quartet (1993), but the writing is changed to 'Albert Fink presents' in the final version of the game.
}

\section{References}

Chion, M. (1994) Audio-vision: Sound on Screen, ed. and trans. by C. Gorbman, New York: Columbia University Press

Collins, K. (2008) Game Sound: An Introduction to the History, Theory and Practice of Video Game Music and Sound Design, Cambridge, MA and London: MIT Press

Crecente, B. (2008) 'No Gods or Kings: Objectivism in BioShock', Kotaku.com.au, 16 February. Accessible at http://www.kotaku.com.au/2008/02/no_gods_or_kings_objectivism_in_BioShock-2/. Accessed 10 December 2013.

Cruz, J. (1999) Culture on the Margins: The Black Spiritual and the Rise of American Cultural Interpretation, Princeton, NJ: Princeton University Press.

Gibbons, W. (2011) 'Wrap Your Troubles in Dreams: Popular Music, Narrative and Dystopia in BioShock', Game Studies, 11, December. Accessible at http://gamestudies.org/1103/articles/gibbons. Accessed 17 December 2013.

Goldfarb, A. (2013) 'The Music of BioShock Infinite', IGN.com, 12 March. Accessible at http://uk.ign.com/articles/2013/03/12/the-music-of-BioShock-infinite. Accessed 17 December 2013.

Granata, C. (2003) Wouldn't it be Nice: Brian Wilson and the Making of the Beach Boys' Pet Sounds, Chicago: Chicago Review Press

Grau, O. (2003) Virtual Art: From Illusion to Immersion, Cambridge, MT: MIT Press Hocking, C. (2007) 'Ludonarrative Dissonance in BioShock: The Problem of What 
the Game is About', Click Nothing [blog], 7 October. Accessible at http://clicknothing.typepad.com/click_nothing/2007/10/ludonarrative-d.html. Accessed 10 December 2013.

Jorgensen, K. (1997) 'On Transdiegetic Sound in Computer Games', Northern Lights: Film and Media Studies Yearbook, 5, September, 105-17

Levine, L. W. (1978) Black Culture and Black Consciousness: Afro-American Folk Thought From Slavery to Freedom, Oxford: Oxford University Press

Packer, J. (2010) 'The battle for Galt's Gulch: BioShock as critique of Objectivism ', Journal of Gaming \& Virtual Worlds, 2, December, 209-24

Schmeink, L. (2009) 'Dystopia, Alternate History and the Posthuman in BioShock', Current Objectives of Postgraduate American Studies, 10. Accessible at http://copas.uni-regensburg.de/article/viewArticle/113/137. Accessed 10 December 2013.

Schulzke, M. (2009) 'Moral Decision Making in Fallout', Game Studies, 9, November. Accessible at http://gamestudies.org/0902/articles/schulzke. Accessed 11 December 2013.

Shuker, R. (2012) Understanding Popular Music Culture, London: Routledge

Tagg, P. (2000) 'Analysing Popular Music: Theory, Method and Practice', in R. Middleton (ed.), Reading Pop: Approaches to Textual Analysis in Popular Music, Oxford and New York: Oxford University Press, pp. 71-103

Tavinor, G. (2009) 'BioShock and the Art of Rapture', Philosophy and Literature, 33, April, 91-106

Travis, R. (2010) 'BioShock in the Cave: Ethical Education in Plato and in Video Games', in K. Schrier and D. Gibson (eds), Ethics and Game Design: Teaching Values through Play, Hershey: Information Science Reference, pp. 86-101

Tulloch, R. (2009) 'Ludic Dystopias: Power, Politics and Play, and Play', Proceedings of the Sixth Australasian Conference on Interactive Entertainment, 13. Accessible at http://delivery.acm.org/10.1145/1750000/1746063/a13-

tulloch.pdf?ip=86.30.34.197\&id=1746063\&acc=ACTIVE\%20SERVICE\&key=C2716F EBFA981EF1B06E1D041E0275EADEA65A8427B800FE\&CFID=269650708\&CFTO $\mathrm{KEN}=81498157 \&$ acm__=1386681551_5152e2b1f8602776ac560bcb945cef35. 
Accessed 10 December 2013

Whalen, Z. (2004) 'Playing Along: An Approach to Videogame Music', Game Studies, 4, November. Accessible at http://www.gamestudies.org/0401/whalen/ Accessed 2 May 2014.

\section{Video Games}

BioShock (2007) 2K Games. Irrational Games [at the time 2K Boston].

BioShock 2 (2010) 2K Marin, 2K Games.

BioShock Infinite (2013) 2K Games. Irrational Games.

Braid (2009) Number None, Inc. Microsoft Game Studios.

Dear Esther (2012) The Chinese Room.

Fez (2012) Polytron. Microsoft Game Studios.

Proteus (2013) Ed Key and David Kanaga. 